\title{
TubeSpin bioreactor 50 for the high-density cultivation of Sf-9 insect cells in suspension
}

\author{
Qiuling Xie • Patrik O. Michel • Lucia Baldi • \\ David L. Hacker $\cdot$ Xiaowei Zhang • \\ Florian M. Wurm
}

Received: 20 August 2010/ Accepted: 23 December 2010/Published online: 26 January 2011

(C) Springer Science+Business Media B.V. 2011

\begin{abstract}
Here we present the TubeSpin bioreactor 50 (TubeSpins) as a simple and disposable culture system for Sf-9 insect cells in suspension. Sf-9 cells had substantially better growth in TubeSpins than in spinner flasks. After inoculation with $10^{6}$ cells $/ \mathrm{ml}$, maximal cell densities of $16 \times 10^{6}$ and $6 \times 10^{6}$ cells $/ \mathrm{ml}$ were reached in TubeSpins and spinner flasks, respectively. In addition the cell viability in these batch cultures remained above $90 \%$ for 10 days in TubeSpins but only for 4 days in spinner flasks. Inoculation at even higher cell densities reduced the duration of the lag phase. After inoculation at $2.5 \times 10^{6} \mathrm{cells} / \mathrm{ml}$, the culture reached the maximum cell density within 3 days instead of 7 days as observed for inoculation with $10^{6}$ cells $/ \mathrm{ml}$. Infection of Sf-9 cells in TubeSpins or spinner flasks with a recombinant baculovirus
\end{abstract}

Q. Xie · P. O. Michel - L. Baldi - D. L. Hacker .

X. Zhang · F. M. Wurm ( $\square)$

Laboratory of Cellular Biotechnology, Institute of

Bioengineering, École Polytechnique Fédérale de

Lausanne, CH J2 506, Station 6, 1015 Lausanne,

Switzerland

e-mail: florian.wurm@epfl.ch

Q. Xie

Institute of Bioengineering, Jinan University, Guangzhou

510632, Guangdong, People's Republic of China

Present Address:

$\mathrm{X}$. Zhang

College of Translational Medicine, Nanchang University,

Nanchang 330031, Jiangxi, People's Republic of China coding for green fluorescent protein (GFP) resulted in similar GFP-specific fluorescence levels. TubeSpins are thus an attractive option for the small-scale cultivation of Sf-9 cells in suspension and for baculovirus-mediated recombinant protein production.

Keywords Baculovirus vector - Bioreactor . Sf-9 cells - Spinner flask - Suspension culture · TubeSpin bioreactor 50

\section{Introduction}

Cultivated insect cells are a commonly used host for the production of recombinant proteins for structure and function studies in conjunction with transgene delivery using recombinant baculovirus vectors (Kost and Condreay 1999; Berger et al. 2004; Kost et al. 2005). Although this approach to protein production is possible with adherent cultures, volumetric scaleup of the culture is more practical with cells in suspension. The suspension cultivation of insect cells is typically performed in spinner flasks, Erlenmeyertype shake flasks, and various types of bioreactors (Ikonomou et al. 2003). However, spinner and shake flasks are the most commonly used containers for suspension cultures due to economical and practical reasons. Nevertheless, there are disadvantages to their use (Marheineke et al. 1998; Deparis et al. 2003; Batista et al. 2005). Neither is scalable to working volumes greater than about one liter, and spinner 
flasks, in particular, have very poor $\mathrm{O}_{2}$ transfer into the liquid phase (Nienow 2006). In addition, there is not an adequate scale-down system for either of these vessels, making the performance of medium- and/or high-throughput experiments impractical.

Here we present $50 \mathrm{ml}$ TubeSpin bioreactor 50 (TubeSpins) as an alternative to spinner and shake flasks for the cultivation of insect cells in suspension. These centrifuge tubes fitted with a cap with a membrane filter were originally developed for mammalian cell culture and are suitable for medium- to high-throughput cell cultivation (DeJesus et al. 2004). We describe conditions for the growth of Sf-9 cells in suspension culture in TubeSpins at densities up to $16 \times 10^{6}$ cells $/ \mathrm{ml}$. In addition, we tested the capacity of Sf-9 cells grown in TubeSpins to support baculovirus-mediated recombinant protein production.

\section{Materials and methods}

Cell culture

Sf-9 cells were adapted to grow in suspension in Sf-900 II SFM (Invitrogen, Basel, Switzerland). For routine maintenance, the cells were cultivated in TubeSpin bioreactor 50 (TPP, Trasadingen, Switzerland) with $10 \mathrm{ml}$ medium and passaged twice per week. The cells were passed by centrifugation at $\sim 1500 \times g$ for $3 \mathrm{~min}$ followed by resuspension of the cell pellet in pre-warmed Sf-900 II SFM at $10^{6}$ cells $/ \mathrm{ml}$ or higher as indicated in the text. The cultures were maintained at $28^{\circ} \mathrm{C}$ in a shaking incubator (shaking diam. of $2.5 \mathrm{~cm}$ and $200 \mathrm{rpm}$ ). In $250 \mathrm{ml}$ spinner flasks, the cells were inoculated in $100 \mathrm{ml} \mathrm{Sf-900} \mathrm{II}$ SFM at $10^{6}$ cells $/ \mathrm{ml}$. The culture was incubated at $28^{\circ} \mathrm{C}$ at a stirring speed of 75-90 rpm. The cell density and viability were determined by the Trypan Blue exclusion method using a Neubauer hemocytometer. The $\mathrm{pH}$ and the concentrations of glucose, lactic acid, glutamine, and ammonium were determined with a Nova analyzer (Nova Biomedical, Waltham, MA).

Baculovirus infection

Sf-9 cells in spinner flasks or TubeSpins were grown to $2 \times 10^{6}$ cells $/ \mathrm{ml}$ and infected with a recombinant baculovirus coding for GFP (courtesy of Dr. Leona Gilbert, University of Jyväskylä, Finland)
(Ojala et al. 2001) at a multiplicity of infection (MOI) of 2-3. Culture samples, $1 \mathrm{ml}$, were collected at various times post-infection (p.i.), and the cells were lysed by addition of $1 \mathrm{ml}$ ice cold lysis buffer [1.0\% (v/ v) Triton X-100, PBS] by gentle mixing for $15 \mathrm{~min}$ at $4^{\circ} \mathrm{C}$ (Oker-Blom et al. 1996). The relative GFPspecific fluorescence units (RFU) were determined for cultures of infected and non-infected cells using a fluorescence plate reader with an excitation wavelength of $395 \mathrm{~nm}$ and an emission wavelength of $509 \mathrm{~nm}$. The RFU in the medium was measured in a 1:1 mix of Sf-900 II SFM and lysis buffer. The RFU value for each lysate was normalized using Eq. 1:

$\frac{R F U_{\text {Cells }}-R F U_{\text {Medium }}}{R F U_{\text {Medium }}} \cdot 100 \%$

\section{Results and discussion}

Batch cultures of Sf-9 cells in TubeSpins and spinner flasks

TubeSpins and spinner flasks, optimized for Sf-9 cell growth without active aeration, were inoculated in parallel with $10^{6}$ cells $/ \mathrm{ml}$. In the former, a maximal of $16 \times 10^{6}$ cells $/ \mathrm{ml}$ was achieved at day 7 post-inoculation (Fig. 1a), and the cell viability remained above 90\% until day 10 (Fig. 1b). In contrast, the cells cultivated in a $250 \mathrm{ml}$ spinner flask only achieved a maximal of $6 \times 10^{6}$ cells/ml (Fig. 1a), and the cell viability dropped below $90 \%$ on day 4 and steadily declined thereafter (Fig. 1b). Our results in spinner flasks matched those already reported for Sf-9 and Sf-21 cells (Gotoh et al. 2004; Chiou et al. 2000). By comparison, $8-12 \times 10^{6}$ cells $/ \mathrm{ml}$ have been reported for batch cultures in shake-flasks (Bovo et al. 2008; Batista et al. 2005). Thus the performance of Sf-9 cells in TubeSpins described here was superior to these two widely used suspension cultivation systems. Overall, the highest cell densities for cultivated Sf-9 cells $\left(\sim 55 \times 10^{6}\right.$ cells $\left./ \mathrm{ml}\right)$ have only been achieved in fedbatch and perfusion cultures using instrumented bioreactors (Jäger 1996; Bédard et al. 1997; Elias et al. 2000).

Nutrient consumption and waste production for Sf-9 cells in TubeSpins

Glucose is the most important carbon source for insect cell cultivation. In some media, such as 

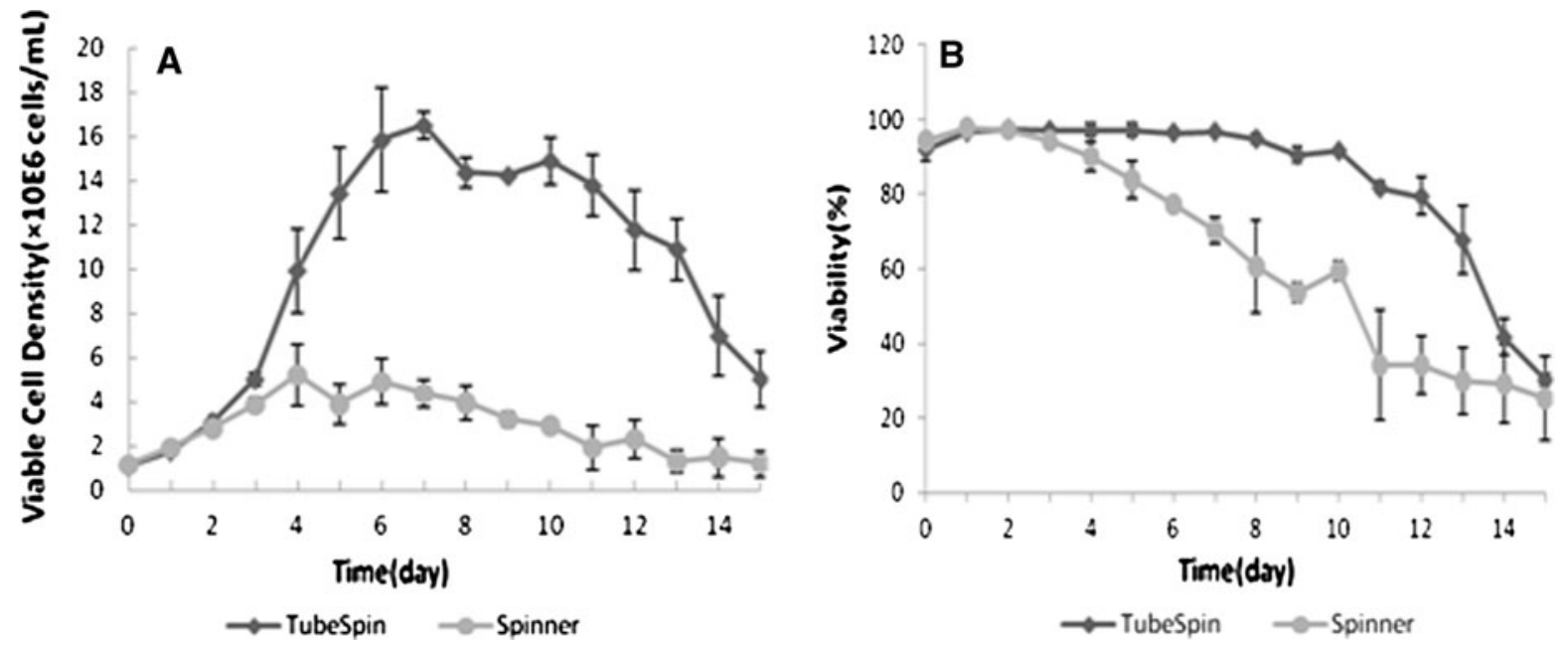

Fig. 1 Growth of Sf-9 cells in batch cultures in TubeSpins and spinner flasks. The cultures were inoculated in duplicate at $10^{6}$ cells/ $\mathrm{ml}$. The cell density (a) and percentage of viability (b) were determined at the times indicated
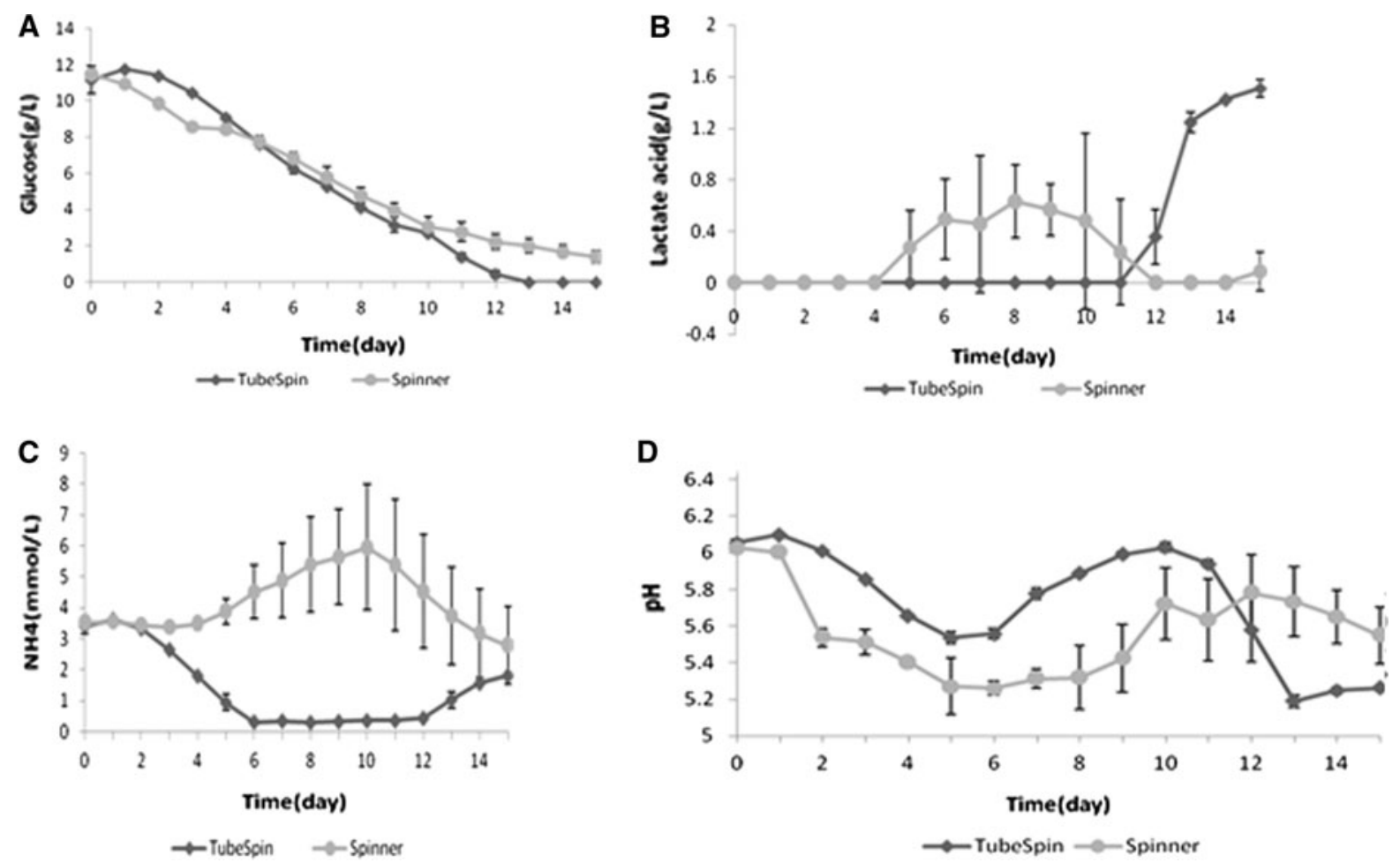

Fig. 2 Comparison of Sf-9 cultures in TubeSpins and spinner flasks. The cultures were inoculated in duplicate at $10^{6}$ cells/ ml. Sampling was performed at the times indicated, and

glucose (a), lactate (b), ammonia (c), and $\mathrm{pH}$ (d) were measured with a Nova analyzer

TNM-FM and IPL-41, glucose may be a growthlimiting factor (Bédard et al. 1993; Drews et al. 1995). For the Sf-9 cell cultures in TubeSpins inoculated at $10^{6}$ cells $/ \mathrm{ml}$, glucose was depleted from

the medium only by day 13 (Fig. 2a), coinciding with the onset of a rapid decline in cell viability (Fig. 1b). For the Sf-9 cells in spinner flasks, the glucose concentration remained above zero throughout the 
15-day batch culture (Fig. 2a). Thus, other factors besides glucose contributed to the reduced cell growth and cell viability for the cultures in spinner flasks as compared to those in TubeSpins.

Glutamine consumption was negligible in Sf-9 cultures in both cell cultivation systems (data not shown). Sf-9 and Sf-21 cells can grow in a glutamine-, glutamate- and aspartate-free medium, provided that ammonium ions are present (Öhman et al. 1996). However, glutamine deprivation may result in a reduced cell growth rate.

Cultivated insect cells normally accumulate lactate to very low levels (Bovo et al. 2008). In line with these observations, lactate was only seen after day 12 for Sf-9 cultures in TubeSpins (Fig. 2b). The level of lactate then rapidly increased as the cell viability decreased. For the cultures in spinner flasks, lactate increased from day 4 to a maximum on day 8 and then declined as the cell viability decreased (Fig. 2b). Sf-9 cells do not produce lactate when sufficiently supplied with $\mathrm{O}_{2}$ even in media with a high initial glucose concentration (Ikonnomou et al. 2003). Thus, the lactate accumulation seen in spinner flasks may have been due to a low level of dissolved $\mathrm{O}_{2}$ in the culture as predicted in this type of cultivation vessel since it has a low volumetric mass transfer coefficient (Nienow 2006).

Sf-9 cells do not usually produce ammonia during cultivation. Furthermore, the growth of Sf-9 cells is not adversely affected by $10 \mathrm{mM}$ ammonium salts (Bédard et al. 1993). For the cultures in TubeSpins, ammonium declined from initially $3.5 \mathrm{mM}$ to its depletion by day 6 (Fig. 2c). Thereafter, as the cell viability declined, the ammonia level gradually increased (Fig. 2c). The reason for the consumption of ammonia in the early stages of the culture in TubeSpins is not known. For the cultures in spinner flasks, the concentration of ammonia increased to about $6 \mathrm{mM}$ by day 10 before declining (Fig. 2c).

The optimal $\mathrm{pH}$ for insect cell culture is between 6.2 and 6.5 because insect tissue fluids normally range from $\mathrm{pH}$ 6.2-6.9 (Grace 1962). The $\mathrm{pH}$ of the cultures in TubeSpins remained in a $\mathrm{pH}$ range between 5.6 and 6.2 until day 12 and then declined to $\mathrm{pH} 5.2$ (Fig. 2d). For the cultures in spinner flasks, the $\mathrm{pH}$ was always lower than for those in TubeSpins until day 12 , and the minimum $\mathrm{pH}$ was 5.3 by day 5 (Fig. 2d). Clearly, the $\mathrm{pH}$ was more suitable for Sf-9 cells in TubeSpins than in spinner flasks and may

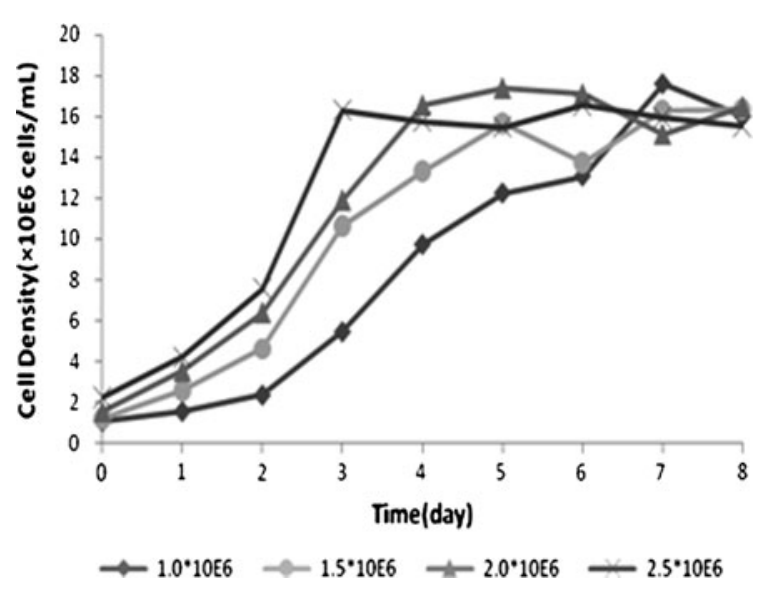

Fig. 3 Effect of inoculation cell density on the growth kinetics of Sf-9 cells in TubeSpin bioreactors. The cells were inoculated at different starting cell densities as indicated. The cell density (a) and viability (b) were determined at the times indicated by manual counting using the Trypan Blue exclusion method. Each culture was performed in triplicate

have contributed to the better cell growth performance in the former.

Inoculation density for Sf-9 cells in TubeSpins

A long lag phase was observed in the Sf-9 culture in TubeSpins following inoculation at $10^{6}$ cells $/ \mathrm{ml}$ (Fig. 1a). To determine if this lag phase was dependent on the inoculation density, Sf-9 cells were inoculated with different cell concentrations in TubeSpin bioreactors. The length of the lag phase decreased as the initial cell density increased (Fig. 3). With an inoculation of $2.5 \times 10^{6}$ cells $/ \mathrm{ml}$, the culture reached the maximum density of $16 \times 10^{6}$ cells $/ \mathrm{ml}$ by day 3 while the same cell density was achieved on day 7 for the culture inoculated with $10^{6}$ cells $/ \mathrm{ml}$ (Fig. 3). The cell viability for the different cultures was similar over the entire cultivation period (data not shown).

Infection of Sf-9 cells with baculovirus in TubeSpins and spinner flasks

To evaluate whether or not the cultivation method affected the efficiency of recombinant protein production, Sf-9 cells in TubeSpins or spinner flasks were infected with a recombinant baculovirus vector coding for GFP (Ojala et al. 2001). Similar levels of GFP-specific fluorescence were observed in the two 


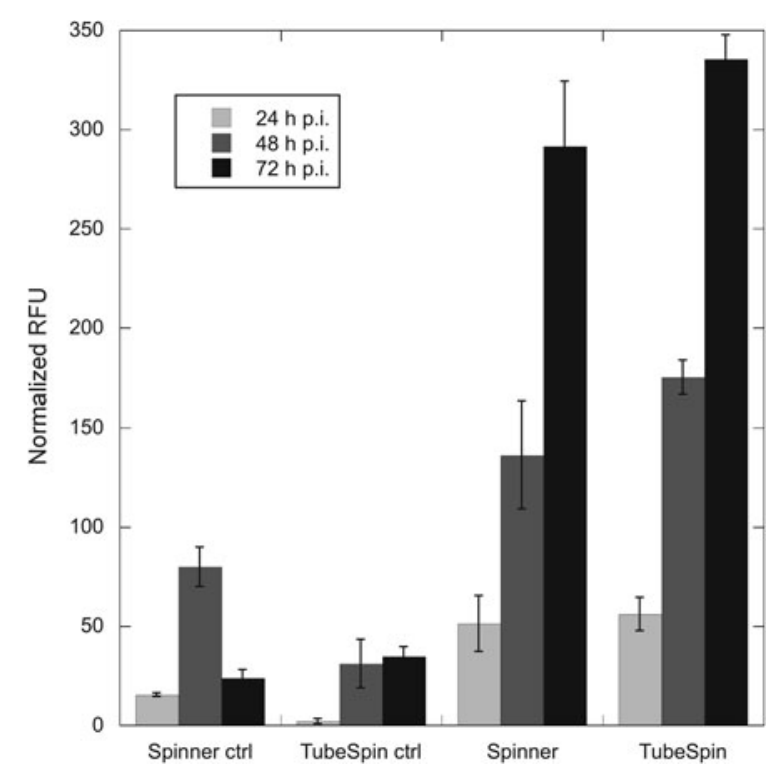

Fig. 4 Comparison of recombinant GFP production in Sf-9 cultures grown in spinner flasks and TubeSpins. The cells at $2 \times 10^{6}$ cells $/ \mathrm{ml}$ were infected with baculovirus at MOI $2-3$ or left uninfected $(c t r l)$. The cultures were analyzed for GFPspecific fluorescence at various times post-infection as indicated. For the cultures in spinner flasks, each bar represents the average of two independent experiments, and for the cultures in TubeSpins, each bar represents the average of two independent experiments performed in duplicate

cultures at each time point (Fig. 4). Similar results were observed for the infection of Sf-9 cells cultivated in Erlenmeyer flasks (data not shown).

\section{Conclusions}

The results show that Sf-9 cells have a better growth performance in TubeSpins than in spinner flasks under the conditions tested here. In batch cultures the maximal cell density was $250 \%$ higher in TubeSpins than in spinner flasks, and the cell viability remained above $90 \%$ for a longer time in TubeSpins than in spinner flasks. Under similar conditions to those used here, the TubeSpins were shown to have a volumetric mass transfer coefficient $\left(\mathrm{k}_{\mathrm{L}} \mathrm{a}\right)>17 \mathrm{~h}^{-1}$ (Zhang et al. 2009). Such a high $\mathrm{k}_{\mathrm{L}}$ a assures oxygen supply through passive air transport into the cultivation vessel to support the high cell density observed here. In contrast, spinner flasks have a $\mathrm{k}_{\mathrm{L}} \mathrm{a}$ of about $2 \mathrm{~h}^{-1}$ under the conditions used here (Nienow 2006; Diao et al. 2008). The high $\mathrm{k}_{\mathrm{L}} \mathrm{a}$ in TubeSpins also assures that the stripping of $\mathrm{CO}_{2}$ occurs efficiently. This may be one reason why reason why the $\mathrm{pH}$ in TubeSpins over the culture period was more moderate that that observed in spinner flasks. Another major advantage of TubeSpins is that cell cultivation can be performed in volumes as low as $2 \mathrm{ml}$. Thus a significant savings in medium costs can be realized. Plus, a large number of TubeSpins can be employed at the same time in a small space, allowing many experimental conditions to be tested at once. Moreover, we have shown that Sf-9 cells grown in TubeSpins are suitable for recombinant protein production using baculovirus vectors. Finally, the orbital-shaking technology described here is scalable and has been tested at volumes up to 1,0001 with mammalian cell cultures (Muller et al. 2005; Zhang et al. 2009).

Acknowledgments The authors thank Dr. Hilal Lashuel of the EPFL for the Sf-9 cells and Dr. Leona Gilbert of the University of Jyväskylä for the recombinant baculovirus. This study was supported by grants from the Guangdong Provincial Department of Science and Technology (2008B030301349), the MOE of China (211 Grant), and the Academy of Finland (decision no. 135820).

\section{References}

Batista FR, Pereira CA, Mendonça RZ, Moraes AM (2005) Enhancement of Sf9 cells and baculovirus production employing Grace's medium supplemented with milk whey ultrafiltrate. Cytotechnology 49(1):1-9

Bédard C, Tom R, Kamen A (1993) Growth, nutrient consumption, and end product accumulation in Sf-9 and BTIEAA insect cell cultures: insights into growth limitation and metabolism. Biotechnol Prog 9(6):615-621

Bédard C, Perret S, Kamen AA (1997) Fed-batch culture of Sf-9 cells supports $3 \times 10^{7}$ cells $/ \mathrm{ml}$ and improves baculovirus-expressed recombinant protein yields. Biotechnol Lett 19:629-632

Berger I, Fitzgerald DJ, Richmond TJ (2004) Baculovirus expression system for heterologous multiprotein complexes. Nat Biotechnol 22(12):1583-1587

Bovo R, Galesi AL, Jorge SA, Piccoli RA, Moraes AM, Pereira CA, Augusto EF (2008) Kinetic response of a Drosophila melanogaster cell line to different medium formulations and culture conditions. Cytotechnology 57(1):23-35

Chiou T-W, Hsieh Y-C, Ho CS (2000) High density culture of insect cells using rational medium design and feeding strategy. Bioprocess Biosyst Eng 22(6):483-491

DeJesus MJ, Girard P, Bourgeois M, Baumgartner G, Jacko B, Amstutz H, Wurm FM (2004) TubeSpin satellites: a fast track approach for process development with animal cells using shaking technology. Biochem Eng J 17:217-223

Deparis V, Durrieu C, Schweizer M, Goergen JL, Chevalot I, Marc A (2003) Promoting effect of rapeseed proteins and peptides on Sf9 insect cell growth. Cytotechnology 42(2):75-85 
Diao J, Young L, Zhou P, Shuler ML (2008) An actively mixed mini-bioreactor for protein production from suspended animal cells. Biotechnol Bioeng 100:72-81

Drews M, Paalme T, Vilu R (1995) The growth and nutrient utilization of the insect cell line Spodoptera frugiperda Sf9 in batch and continuous culture. J Biotechnol 40:187-198

Elias CB, Zeiser A, Bédard C, Kamen AA (2000) Enhanced growth of Sf-9 cells to a maximum density of $5.2 \times 10(7)$ cells per $\mathrm{ml}$ and production of beta-galactosidase at high cell density by fed batch culture. Biotechnol Bioeng 68(4):381-388

Gotoh T, Chiba K, Kikuchi K-I (2004) Oxygen consumption profiles of Sf-9 insect cells and their culture at low temperature to circumvent oxygen starvation. Biochem Eng $\mathrm{J}$ 17(2):71-78

Grace TD (1962) Establishment of four strains of cells from insect tissues grown in vitro. Nature 195:788-789

Ikonomou L, Schneider Y-J, Agathos SN (2003) Insect cell culture for industrial production of recombinant proteins. Appl Microbiol Biotechnol 62(1):1-20

Jäger V (1996) Perfusion bioreactors for the production of recombinant proteins in insect cells. Cytotechnology 20:191-198

Kost TA, Condreay JP (1999) Recombinant baculoviruses as expression vectors for insect and mammalian cells. Curr Opin Biotechnol 10(5):428-433

Kost TA, Condreay JP, Jarvis DL (2005) Baculovirus as versatile vectors for protein expression in insect and mammalian cells. Nat Biotechnol 23(5):567-575
Marheineke K, Gruënewald S, Christie W, Reiländer H (1998) Lipid composition of Spodoptera frugiperda ( $\mathrm{Sf} 9$ ) and Trichoplusia ni (Tn) insect cells used for baculovirus infection. FEBS Lett 441(1):49-52

Muller N, Girard P, Hacker DL, Jordan M, Wurm FM (2005) Orbital shaker technology for the cultivation of mammalian cells in suspension. Biotechnol Bioeng 89(4):400-406

Nienow AW (2006) Reactor engineering in large scale animal cell culture. Cytotechnology 50(1-3):9-33

Öhman L, Alarcon M, Ljunggren J, Ramqvist A-K, Häggström $\mathrm{L}$ (1996) Glutamine is not an essential amino acid for Sf-9 insect cells. Biotechnol Lett 18(7):765-770

Ojala K, Mottershead DG, Suokko A, Oker-Blom C (2001) Specific binding of baculoviruses displaying gp64 fusion proteins to mammalian cells. Biochem Biophys Res Commun 284:777-784

Oker-Blom C, Orellana A, Keinanen K (1996) Highly efficient production of GFP and its derivatives in insect cells for visual in vitro applications. FEBS Lett 389:238-243

Zhang X, Bürki C-A, Stettler M, De Sanctis D, Perrone M, Discacciati M, Parolini N, DeJesus M, Hacker DL, Quarteroni A, Wurm FM (2009) Efficient oxygen transfer by surface aeration in shaken cylindrical containers for mammalian cell cultivation at volumetric scales up to 1000 L. Biochem Eng J 45:41-47 